\title{
Variance Persistence in the Greater China Region: A Multivariate GARCH Approach
}

\author{
John Francis Diaz", Peh Ying Qian** and Genevieve Liao \\ $\operatorname{Tan}^{* * *}$
}

\begin{abstract}
This paper utilizes three Multivariate General Autoregressive Conditional Heteroscedasticity (MGARCH) models to determine variance persistence in the Greater China region from 2009 to 2014. The first approach applies the Baba, Engle, Kraft and Kroner (BEKK) model and shows that the Shanghai Stock Exchange Composite Index (SSEI), Taiwan Capitalization Weighted Stock Index (TAEIX) and the Hang Seng Stock Index (HSEI) stock returns are all functions of their lagged covariances and lagged cross-product innovations. The second MGARCH approach applies two methodologies, namely, dynamic conditional correlation (DCC), and constant conditional correlation (CCC) estimations. The DCC model concludes both short- and long-run persistencies between Taiwan's TAIEX and Hong Kong's HSEI. Alternatively, the CCC model confirms the initial findings of the BEKK model, and adds that the relationships among these three strong economies are stable in the long-run. The log-likelihood values determine that the DCC model is better in judging volatility dynamics in the Greater China region, because of economic clauses brought by the Closer Economic Partnership Arrangement (CEPA), the Economic Co-operation Framework Agreement (ECFA) and the Hong Kong - Taiwan Business Cooperation Committee (BCC).
\end{abstract}

Keywords: Greater China Region, stock market returns, volatility dynamics, MGARCH models.

JEL classification: C30, P45.

\footnotetext{
* PhD, CEA, Associate Professor, Department of Finance \& Department of Accounting, College of Business, Chung Yuan Christian University, Chung-Li, Taiwan. Email: di.jian@cycu.edu.tw; Johnfrancis_diaz@yahoo.com

** IMBA, International Master of Business Administration Program, College of Business, Chung Yuan Christian University, Chung-li City, Taiwan. Email: iris08138@ gmail.com

${ }^{* \star \star}$ IMBA, International Master of Business Administration Program, College of Business, Chung Yuan Christian University, Chung-li City, Taiwan. Email: gen_liaotan@yahoo.com
} 


\section{Introduction}

The Greater China Region is a label generally used to refer to the economic and cultural ties among the relevant territories of China, Taiwan and Hong Kong. With the implementation of free market reforms and subsequent opening to global trade in 1978, the economy of mainland China has become one of the world's top economic performers. Hong Kong is one of the Asian region's main economic hubs, having an economy that has become a center of financial and high-technology industries. Taiwan is consistently one of the fastest growing economies in East Asia with its strong reliance on electronics and semi-conductor industries.

The growing integration within the Greater China Region has become more evident with signed trade agreements among these economies. The return of Hong Kong's sovereignty to mainland China in 1997 led to stronger integration between these two economies, paving the way to the signing of the Closer Economic Partnership Arrangement (CEPA) on 29 June 2003. The CEPA aimed to decrease restrictions like tariffs and quotas to ensure a smoother flow of goods and services between China and Hong Kong. The arrangement also agreed to follow the international rules mandated by the World Trade Organization (WTO). Mainland China is currently the largest trading partner of Hong Kong with a total trade of US $\$ 73.34$ billion of exports, which accounts for $42 \%$ of Hong Kong's total exports; and US $\$ 38.87$ billion of imports, or $16 \%$ of total imports (WTO, 2014). CEPA is an agreement that brings benefit to both China and Hong Kong by providing greater access for Hong Kong's businesspeople to invest in Mainland China, while the latter could use the former's economy as a springboard to reach out to the global market (Trade and Industry Department, 2012).

Taiwan's economic relationship with China was also strengthened with the signing of the Economic Co-operation Framework Agreement (ECFA) in June 2010. The agreement further expanded their bilateral trading relationship, as well as their commercial linkage with the rest of the world (Morrison, 2003). The ECFA boosted the current total exports of China to Taiwan by approximately US $\$ 7.88$ billion (4.5 per cent), while the total imports account for 2.5 per cent, which is valued at US\$5.91 billion (WTO, 2014). This has made Taiwan one of Mainland China's top ten main trading partners. The economic transaction between China and Taiwan is expected to grow further with the signing of the Cross-strait Service Trade Agreement (CSST) on 21 June 2013. 
Taiwan's close economic relationship with Hong Kong was cemented in April 2010 with the establishment of the Hong Kong-Taiwan Business Cooperation Committee (BCC). Each of the two economies is the other's fourth largest trading partner. This trading relationship is also expected to expand with the Taiwan-Hong Kong Economic and Cultural Co-operation Council (THEC) serving as the discussion platform from which economic and public policies can be coordinated between the two economies. This will also serve the interests of Mainland China. In 2013, a total bilateral trade of US $\$ 34.6$ billion was routed from Taiwan to Hong Kong to China (Hong Kong Economic, Trade and Cultural Office, 2014).

The economic integration in the Greater China region has become an important topic for Asian economists, as the region, particularly China in recent decades, has been experiencing noteworthy growth. This is the primary motivating factor of our study and, to the best of our knowledge, studies on the volatility correlations among the region's major stock markets are still unchartered. This research explores the application of multivariate GARCH models to the stock markets of Shanghai Stock Exchange (SSEI), Taiwan Stock Exchange Index (TAIEX) and Hong Kong Stock Exchange (HSEI). The paper is motivated by the absence of empirical studies looking at the volatility linkages of the Greater China Region using MGARCH models.

MGARCH models are formulated to model conditional covariance matrices of multiple time-series, which offer relevant information on risk measures and spillover related to a set of financial instruments. The first MGARCH model was introduced by Bollerslev (1990), through the constant conditional correlation (CCC) model. The CCC model improves the estimates by using non-parametric models, and by extending the correlation to a more adaptive model. The second MGARCH model was proposed by Engle and Kroner (1995), through the synthesized Baba, Engle, Kraft and Kroner (BEKK) model, which allows cross dynamics of conditional covariances. Engle (2002) augmented a constrained dynamism in the correlations through the dynamic conditional correlation (DCC) model, in which the dynamics are limited to be equal for all correlations.

This paper analyzes the volatility dynamics among SSEI, TWSE and HKSE using three multivariate volatility models, namely diagonal BEKK, CCC and DCC. The paper also compares the performances of these models to identify which of the multivariate methods considered is best to model the stock markets of the Greater China Region. This paper contributes to 
the literature by revisiting the volatility relationship of the major stock markets in the Great China Region. The objectives of this study are:

- to identify the presence of long- and short-run persistence in the relationships among SSEI, TAEIX and HSEI returns;

- to determine if the volatility of Greater China's major stock returns is transmitted within the markets through their own conditional variances or even conditional covariances;

- to examine if returns related relationships are constant over time or vary over time; and

- to identify which multivariate model can best determine the relationship among the stock markets of SSEI, TAEIX and HSEI.

The paper is written as follows: Section 2 reviews related studies, Section 3 describes the data and methodology of diagonal BEKK, CCC and DCC models; Section 4 interprets the empirical findings; and Section 5 presents the conclusion.

\section{Related Literature}

This section provides an overview of studies determining the relationships between the volatilities and co-volatilities of the major stock markets in the Greater China Region. The papers cited are taken from two groups of literature: (1) literature that has established return and volatility connections between financial market instruments, and (2) studies that have shown the suitability of GARCH models in modeling markets in the Greater China Region.

The globalization of financial markets created a tendency for volatilities to move across financial markets without any regard for boundaries, as shown by the studies of Hafner and Herwartz (2006) and Bubak, Kocenda and Ikes (2011) using exchange rates, and Karolyi (1995) and Zhu (2009) in stock markets. Studies also have shown that financial asset returns volatility, correlations and covariances changed from time to time with persistent dynamics as concluded by Fleming, Kirby and Ostdiek (1998). Moreover, Li, Su and Qiao (2016) observed that the co-movement between the stock market was a result of the economic policies of various countries, the co-movement of international markets, and the impact of national financial regulations. 
It has also been shown that financial asset returns volatility, covariances and correlations changed over time with persistent dynamics, as seen by Fleming et al. (1998) in the bond and stock markets and $\mathrm{Du}, \mathrm{Yu}$ and Hayes (2011) in the commodities markets. According to Bauwens, Laurent and Rombouts (2006), modeling these financial data characteristics through a multivariate framework can result in more relevant empirical models than working with separate univariate models. Jiang, Nie and Monginsidi (2017) observed the co-movement between the yields and volatility of the stock market indices in the ASEAN region. The study found that the co-movement was stronger in the short-term and the impact of economic fluctuations on the stock market was temporary.

Regarding the Asian market, particularly the Greater China region, So and Tse (2009) have found that the Asian region is becoming increasingly integrated, using an MGARCH model with tail dependence coefficient. The authors also have argued that there is strong evidence that integration during periods of financial distress are becoming stronger. The study of Yi, Heng and Wong (2009), on the other hand, by using a fractionally integrated vector error correction model combined with an MGARCH model, found that China's stock market has a strong linkage with Hong Kong. Moreover, Moon and Yu (2010) studied the linkages between the US and Chinese stock markets using a univariate GARCH model. The paper found that China's stock market has more information influence on the international stock market transmission because of more liquidity and expanding influence. Dynamic correlations using the MGARCH approach were observed earlier by Barari, Lucey and Voronkova (2006) using iShares ETFs to investigate diversification opportunities. The findings of the study showed the presence of timevarying conditional correlations in both the short- and long-run dynamics of ETFs. The power of the MGARCH models was also observed by Ho, Tsui and Zhang (2009), Zhu (2009) and Chang, McAleer and Tansuchat (2011) who have examined the US business cycle, Chinese stock returns and crude oil spot and futures returns, respectively. Zhang (2017) studied the interaction of the global stock market co-movements and found that the Chinese stock market's yield and volatility co-movement with the international market were strengthened during a crisis period, and that it maintained closer co-movement with other stock markets after the crisis.

The study of Yilmaz (2010), using the forecast error variance decomposition from a vector autoregression model, has discovered that China's stock market has deepening significance in international markets, particularly in Asia. This was confirmed by the paper of Allen, Amram and 
McAleer (2013) which used multivariate VARMA and univariate GARCH. The authors studied volatility spillovers of China into some advanced countries (i.e., Australia, Hong Kong, Singapore, Japan and USA). Findings show the growing presence of China, and the existence of volatility spillovers across these markets. The authors also showed evidence of nonconstant correlations and a period of negative correlations during the subprime mortgage crisis.

\section{Data and Methodology}

In determining the evidence of volatility dynamics in the Greater China Region, this section uses daily closing prices of SSEI, TAEIX and HSEI from the Taiwan Economic Journal Database beginning from 10 June 2009 to 5 September 2014. The data coverage was chosen right after the subprime mortgage crisis in order to eliminate the high volatility regime previously experienced, which may cause some biases in the analysis of the time-series data. As of October 2014, the total market capitalization of SSEI was approximately US $\$ 2.96$ trillion; HSEI was approximately US\$3.26 trillion; and TAIEX was approximately US $\$ 849.45$ billion. This part of the paper expounds upon the three MGARCH models, namely the BEKK, CCC and DCC models.

\subsection{Baba, Engle, Kraft and Kroner Model}

The BEKK model was proposed by Engle and Kroner (1995) to adapt to the presence of dynamic conditional correlations. The model has the characteristic that the conditional covariance matrices can only be positive. The BEKK model for multivariate $\operatorname{GARCH}(1,1)$ is shown below:

$$
H_{t}=C^{\prime} C+A^{\prime} \varepsilon_{t-1} \varepsilon_{t-1}^{\prime} A+B H_{t-1} B
$$

The individual elements of matrices $\mathrm{C}, \mathrm{A}$ and $\mathrm{B}$ are represented as:

$$
A=\left[\begin{array}{l}
a_{11} a_{12} \\
a_{21} a_{22}
\end{array}\right], \quad B=\left[\begin{array}{l}
b_{11} b_{12} \\
b_{21} b_{22}
\end{array}\right], \quad C=\left[\begin{array}{l}
c_{11} 0 \\
c_{21} c_{22}
\end{array}\right] \text {. }
$$

Given $\sum_{j=1}^{q} \sum_{k=1}^{K}\left(A_{k j} \otimes A_{k j}\right)+\sum_{j=1}^{q} \sum_{k=1}^{K}\left(B_{k j} \otimes B_{k j}\right), \otimes$ denotes the Kronecker product of two matrices, which are less than one in the modulus for covariance stationary (Silvennoinen \& Terasvirta, 2008; Chang et al., 2011). The conditional variances are functions of their lagged values and lagged squared stock value shocks, while the conditional covariances are 
functions of the lagged covariances and lagged cross-country of the corresponding stock value shocks from the diagonal formulation. This demonstration ensures that $H_{t}$ is positive definite for all $t$.

The BEKK $(1,1)$ model has $N(5 N+1) / 2$ parameters (Caporin \& McAleer, 2008, 2009). Given the equation $B=A D$ where $D$ is a diagonal matrix, the number of estimated parameters is decreased, and above equation will be changed to:

$$
H_{t}=C^{\prime} C+A^{\prime} \varepsilon_{t-1} \varepsilon_{t-1}^{\prime} A+D^{\prime} E\left[A^{\prime} \varepsilon_{t-1} \varepsilon_{t-1}^{\prime} A\right] D,
$$

Where

$\alpha_{i i}^{2}+b_{i i}^{2}<1, i=1,2$ represents a stationary series. The parameters of the covariance equation $\left(h_{i j, t}, i \neq j\right)$ are results of the subsequent parameters of the two variance equations $\left(h_{i j, t}\right)$.

\subsection{Constant Conditional Correlations Model}

The CCC multivariate GARCH model was proposed by Bollerslev (1990) and provides better estimates by using non-parametric models and by having a more suitable model for the constant conditional correlation. CCC can be demonstrated below:

$$
\begin{aligned}
& y_{t}=E\left(y_{t} \mid F_{t-1}\right)+\varepsilon_{t}, \varepsilon_{t}=D_{t} \eta_{t}, \\
& \operatorname{var}\left(\varepsilon_{t} \mid F_{t-1}\right)=D_{t} \Gamma D_{t},
\end{aligned}
$$

where

$$
y_{t}=\left(y_{1 t, \ldots,} y_{m t}\right)^{\prime}, \eta_{t}=\left(\eta_{1 t, \ldots,}, \eta_{m t}\right)^{\prime} \text { denotes a series of independently }
$$
and identically distributed (iid) random vectors;

$F_{t-1}$ represents the previous available information at particular time $\mathrm{t} ; D_{t}=\operatorname{diag}\left(h_{1}^{1 / 2}, \ldots, h_{m}^{1 / 2}\right), m$ are the number of returns, and $t=1, \ldots, n$.

McAleer (2005) and Bauwens et al. (2006) further expanded the model by setting the constant conditional correlation matrix of the 
unconditional shocks, $\eta_{t}$, equal to the constant conditional covariance matrix of the conditional shocks, $\varepsilon_{t}$, from Eq. (4). Note that, $\varepsilon_{t} \varepsilon_{t}^{\prime}=D_{t} \eta_{t} \eta_{t}^{\prime} D_{t}, D_{t}=\left(\operatorname{diag} Q_{t}\right)^{1 / 2}$, and $E\left(\varepsilon_{t} \varepsilon_{t}^{\prime} \mid F_{t-1}\right)=Q_{t}=D_{t} \Gamma D_{t}$, with $\Gamma=E\left(\eta_{t} \eta_{t}^{\prime} \mid F_{t-1}\right)=E\left(\eta_{t} \eta^{\prime}\right)$, where $\Gamma=\left\{\rho_{i j}\right\}$ for $i, j=1, \ldots, m . Q_{t}$ stand for the conditional covariance matrix, which is a positive definite if all the conditional variances are positive and $\Gamma$ is positive.

The assumption of a constant conditional variance for each return, $h_{i t}, i=1, \ldots, m$, is a univariate GARCH process, and is represented as:

$$
h_{i t}=\omega_{i}+\sum_{j=1}^{r} \alpha_{i j} \varepsilon_{i, t-j}^{2}+\sum_{j=1}^{s} \beta_{i j} h_{i, t-j}^{2}
$$

where

$\alpha_{i j}$ represents the ARCH effect, or the short run persistence of shocks to return $i$,

$$
\begin{aligned}
& \beta_{i j} \text { denotes the GARCH effect, and } \\
& \sum_{j=1}^{r} \alpha_{i j}+\sum_{j=1}^{s} \beta_{i j} \text { stands for long run persistence. }
\end{aligned}
$$

\subsection{Dynamic Conditional Correlation Models}

The DCC model was formulated by Engle (2002) and proposed to generate a time-dependent conditional correlation matrix. The model suggests the following form:

$$
\begin{aligned}
& y_{t} \mid F_{t-1}+\varepsilon_{t}, \varepsilon_{t}=D_{t} \eta_{t} \sim N\left(0, Q_{t}\right), t=1,2, \ldots, n, \\
& Q_{t}=D_{t} \Gamma D_{t},
\end{aligned}
$$

where

$$
D_{t}=\operatorname{diag}\left(h_{1}^{1 / 2}, \ldots, h_{m}^{1 / 2}\right) \text { denotes a diagonal matrix of conditional }
$$
variances, and 
$F_{t}$ represents the information set at time $t$.

The conditional variance, $h_{i t}$, follows a univariate GARCH model, given as

$$
h_{i t}=\omega_{i}+\sum_{k=1}^{p} \alpha_{i k} \varepsilon_{i, t-k}^{2}+\sum_{l=1}^{q} \beta_{i j} h_{i, t-l}^{2}
$$

Given $\eta_{t}$ as a vector of iid random variables, with zero mean and unit variance, $Q_{t}$ in Eq. (7) stands for conditional covariance matrix (after standardization, $\eta_{i t}=y_{i t} / \sqrt{h_{i t}}$ ). The $\eta_{i t}$ is used to estimate the DCC as below:

$$
\Gamma_{t}=\left\{\operatorname{diag}\left(Q_{t}\right)^{-1 / 2}\right\} Q_{t}\left\{\operatorname{diag}\left(Q_{t}\right)^{-1 / 2}\right\},
$$

where the $k x k$ symmetric positive definite matrix $Q_{t}$ is calculated as:

$$
Q_{t}=\left(1-\theta_{1}-\theta_{2}\right) \bar{Q}+\theta_{1} \eta_{t-1} \eta_{t-1}^{\prime}+\theta_{2} Q_{t-1}
$$

where

$\theta_{1}$ and $\theta_{2}$ express the scalar parameters that stands for the effects of past shocks and past dynamic conditional correlations on the present dynamic conditional correlation.

These are also non-negative scalar parameters that fulfill the condition $\theta_{1}+\theta_{2}<1$, which also means that $Q_{t}>0 . Q_{t}$ in Eq. (7) is a conditional covariance matrix, given $\theta_{1}=\theta_{2}=0$, and $\bar{Q}$ is the $k x k$ unconditional variance matrix of $\eta_{t}$.

The DCC model is non-linear, but may be estimated by using a twostep method: (1) utilizing a series of univariate GARCH estimates, and (2) adapting a correlation estimates, all based on the likelihood function (Caporin and McAleer, 2009). 


\section{Empirical Results}

The study initially filtered the data using univariate filters and showed that the alternative of no unit roots is not rejected in all stock market returns through the Augmented Dickey-Fuller (ADF) unit-root test, meaning the data are stationary. The minimum value of the Akaike Information Criterion (AIC) was applied to determine the lag 1,1 orders of the ARMA and GARCH models. Also, according to the results, the null hypothesis of no serial correlation cannot be rejected for all the stock indices through the Breush-Godfrey Lagrange Multiplier test. In testing for the ARCH effect, the Lagrange Multiplier Test (ARCH-LM) was used (Engle, 1982). The relevant statistics of the ARMA model with the null hypothesis of no ARCH effect for all samples were rejected. The results of the test showed that there is no autoregressive conditional heteroscedasticity for all the univariate samples.

\subsection{Baba, Engle, Kraft and Kroner model results}

Table 1 illustrates the results of the diagonal BEKK model. The test proposed by Hosking (1980) and Li and McLeod (1981) was also utilized to determine if multivariate ARCH effects are present. All data samples showed that the MGARCH model can be applied to the time-series, and presented statistically significant elements of the parameter matrices, A and $\mathrm{B}$ of the diagonal BEKK model. This means that for the values of alpha (A matrix), conditional variances depend only on their own lags, wherein the return volatilities can be determined by their lagged values. For the values of beta (B matrix), the conditional covariances of the Greater China stock returns are also a function of their lagged covariances or the lagged cross-products of the shocks. This means that volatilities are not only determined by their lagged values, but cross volatility spillovers are also present for the whole data set.

The significant results of the $C$ matrix have also shown that the diagonal BEKK model has proved that volatilities of the three major stock indices in the Greater China Region have an impact on each other. The findings of this study with regard to the power of the diagonal BEKK model are consistent with the papers of Worthington, Kay-Spratley and Higgs (2005), studying Australian spot electricity prices, and Chang et al. (2011), studying Brent and WTI crude oil spot and futures returns. 


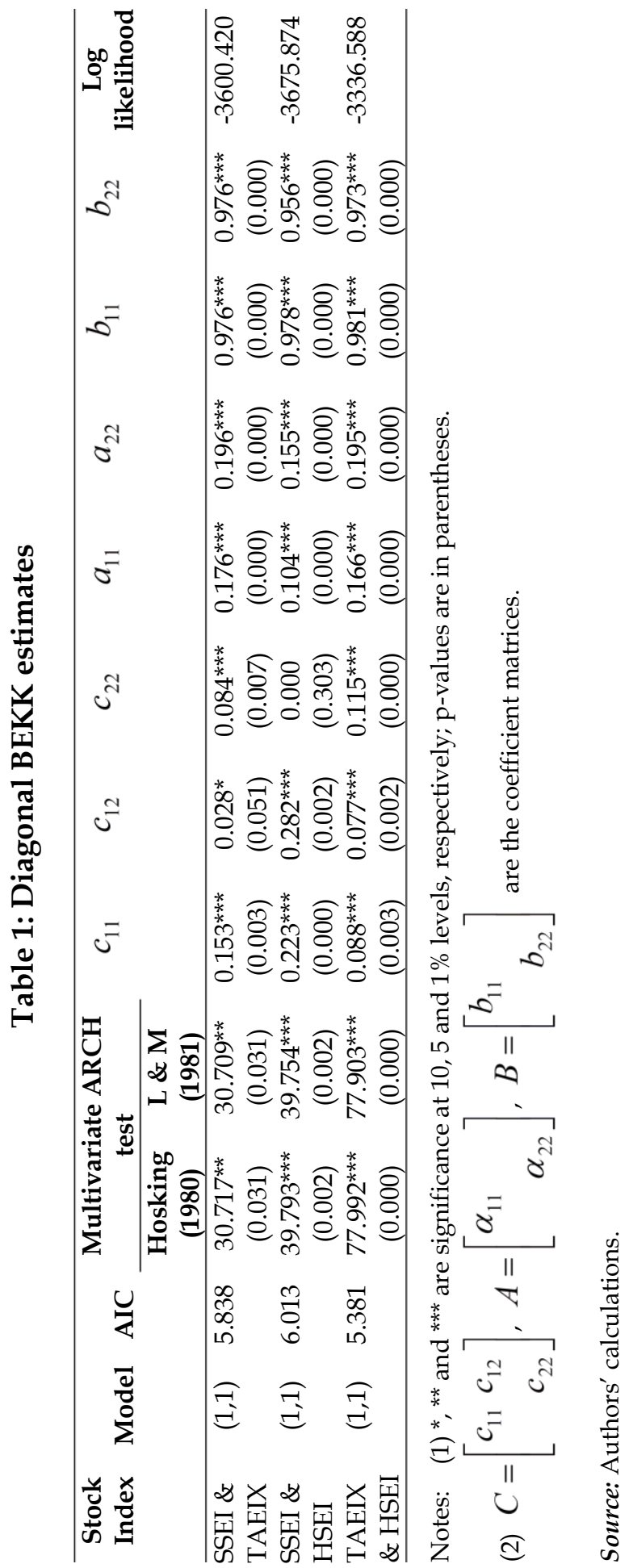




\subsection{Dynamic Conditional Correlation Model Results}

Table 2 shows the results of the DCC model. The test proposed by Hosking (1980) and Li and McLeod (1981) was utilized to determine the presence of multivariate ARCH effects and all data samples again showed the applicability of the MGARCH model. Consistent with the earlier findings, this paper also observed that all the $\mathrm{ARCH}(\alpha)$ and $\mathrm{GARCH}$ $(\beta)$ estimates in the Greater China Region are significant. Our results show that a long-run persistence is evident for the stock returns time-series of China, Taiwan and Hong Kong. In looking at the DCC estimates, only China-Taiwan and Taiwan-Hong Kong supported a short-run persistence of shocks based on the $1^{\text {st }}$ DCC parameter of 0.068 and 0.015 , respectively. However, only with Taiwan-Hong Kong has the $2^{\text {nd }}$ DCC parameter confirmed the presence of a long-run persistence of shocks in their conditional correlations with 0.978 . This means that the volatility relationship of Taiwan and Hong Kong is dynamic.

The results of $\alpha+\beta<1$ satisfies the second moment and $\log$ moment requisites that are sufficient conditions for the Quasi Maximum Likelihood Estimator (QMLE) to be consistent and asymptotically normal (McAleer, Chan \& Marinova, 2007). The hypothesis of time-varying conditional correlations was proven when the higher values of loglikelihood pointed to the DCC estimates as a better model compared to the CCC. However, we can only conclude this finding for Taiwan and Hong Kong, which again corroborates the initial findings of Johansson and Ljungwall (2009). Dynamic correlations between investment instruments were also observed in the studies of Ho et al. (2009), Zhu (2009) and Chang et al. (2011) that examined the US business cycle, China stock returns and crude oil spot and futures returns, respectively. In comparing the loglikelihood values, results show that the CCC model is better for China and Taiwan; and Taiwan and Hong Kong. This demonstrates a significant economic relationship among these countries with increasing economic integration likely to occur in the future. 


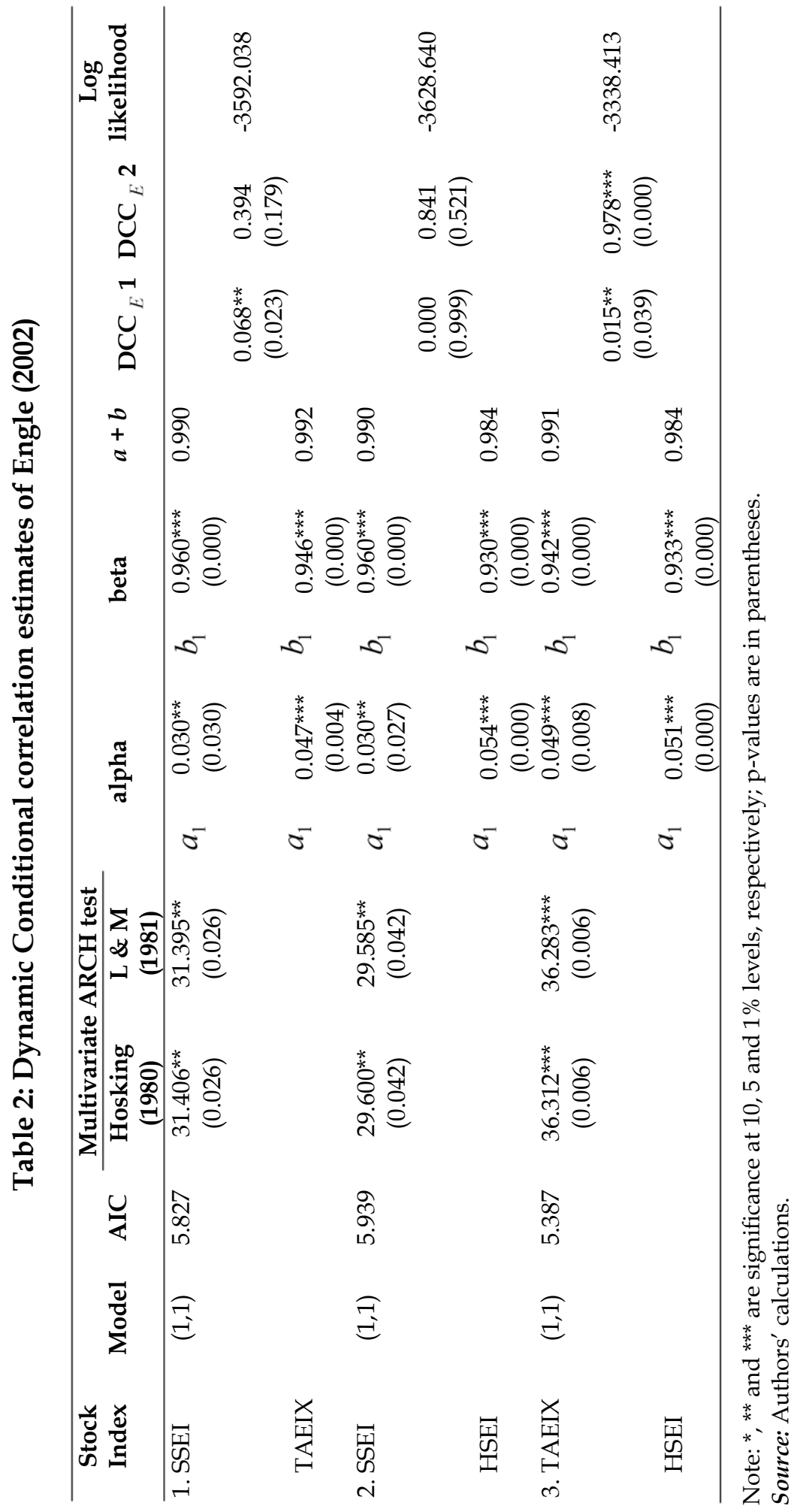




\subsection{Constant Conditional Correlation Model Results}

Table 3 illustrates the estimates of the CCC model. The test proposed by Tse (2000) and Engle and Sheppard (2001) was used to check the multivariate $\mathrm{ARCH}$ effects for constant correlations. The former identified the applicability of the MGARCH model, while the former confirmed the results for the Shanghai Stock Exchange and the Taiwan Stock Index. All ARCH $(\alpha)$ and GARCH $(\beta)$ estimates are significant for the Greater China Region. We conclude that a long-run persistence is present, wherein changes and shocks in the volatility series of the stock returns of China, Taiwan and Hong Kong have impacts on each other's' stock markets into the future.

The findings for $\alpha+\beta<1$ satisfies the second moment and $\log$ moment requisites that are sufficient conditions for the QMLE to be consistent and asymptotically normal (McAleer et al., 2007). These necessary conditions are also used in the study of Chang et al. (2011) on crude oil spot and futures returns. The CCC estimates among the volatility of the Greater China Region's stock index returns are significant, which confirms that there are constant return volatility relationships among the stock exchanges of these economies, and they may not change over time. The highest CCC estimate is 0.582 between Taiwan and Hong Kong, which supports the initial findings of Johansson and Ljungwall (2009) that Taiwan and Hong Kong have a strong bilateral relationship. The lowest CCC estimate is 0.367 between China and Taiwan, which is expected according to Yi et al. (2009) that found China and Hong Kong have a stronger volatility linkage. Our findings of a constant conditional volatility are also consistent with the findings of Malliaropulos (1997) who used MGARCH models to discover that the seven major currencies against the US dollar behaved uniformly over time. 


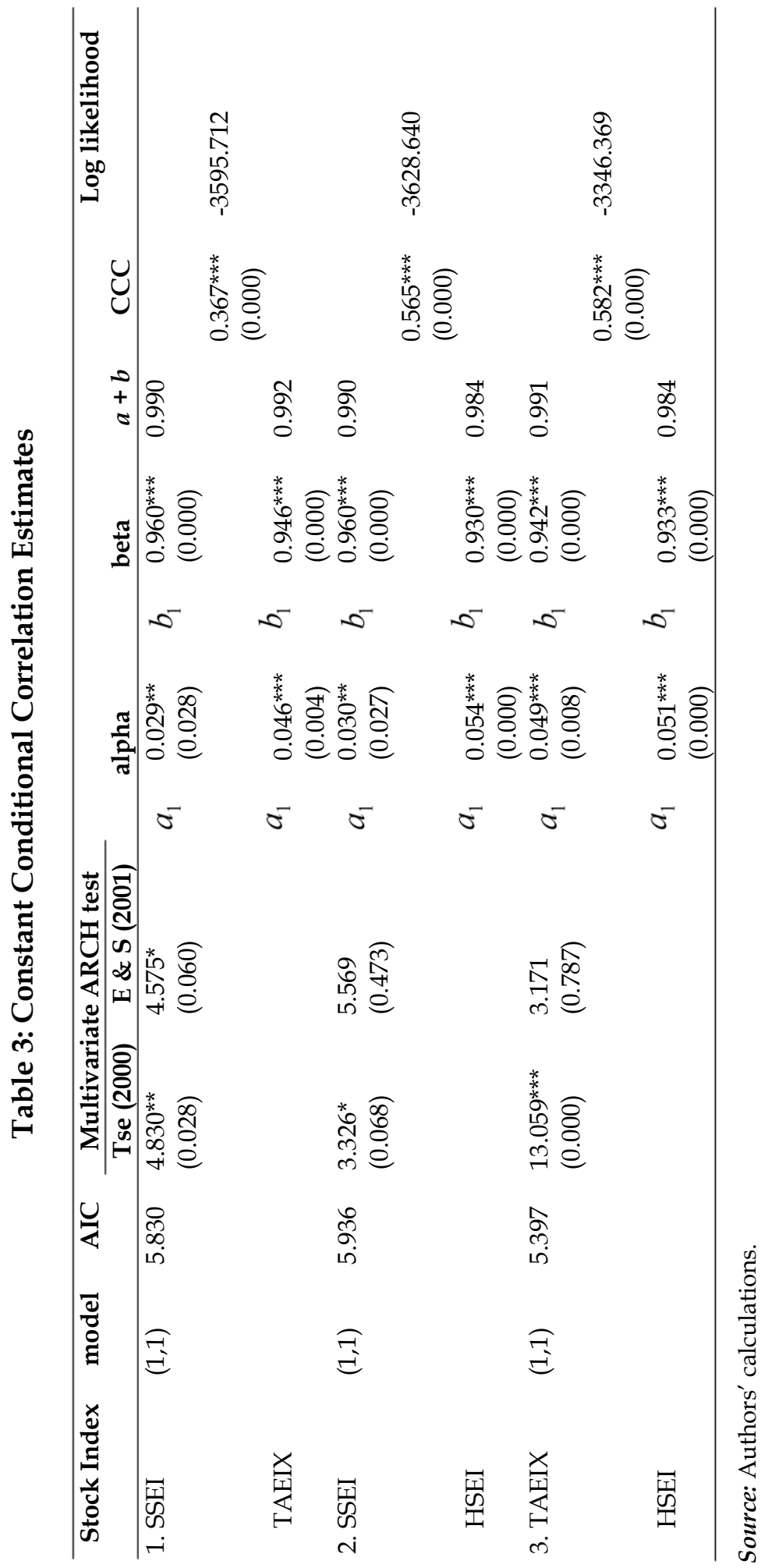




\section{Conclusions}

This research utilizes three MGARCH models to analyze volatility dynamics in the Greater China Region from 1 July 2009 to 5 September 2014. The first methodology applies the BEKK model, which is a general methodology to identify volatility relationships between two data series. The BEKK model found that China's SSEI, Taiwan's TAEIX, and Hong Kong's HSEI stock returns are all functions of their lagged covariances and lagged cross-product innovations. These findings mean that financial market integration in the Greater China Region is increasing as a result of the growing commercial integrations of the three economies, namely the CEPA, ECFA and BCC. The second MGARCH approach applies two methodologies: the DCC model and the CCC model. The DCC model concludes both the short- and long-run persistencies between Taiwan's TAIEX and Hong Kong's HSEI. This implies that short-term co-movements in the volatility may increase in the long run. However, the model only finds short-run persistence between China's SSEI and Taiwan's TAEIX, which may be attributed in the political uncertainties plaguing these two economies. On the other hand, the CCC model confirms the initial findings of the BEKK model, and adds that the relationships among these three economies are stable in the long-run. The loglikelihood values, which measure the best fitting model, favor the DCC model over the CCC estimation indicating that the DCC model is indeed the better tool in judging volatility dynamics in the Greater China Region, particularly in the Taiwan and Hong Kong stock markets. This may be because of economic clauses brought by the $\mathrm{BCC}$, which can maintain current relationship strength and remain stable in the long-term.

The study, given its contribution, is not without its limits. First, the paper did not control for some country-specific variables (e.g., China's more prominent political dominance compared to Hong Kong and Taiwan) that may also affect financial market movements. Second, the study did not consider structural changes in the financial markets, or structural changes in the time-series data.

However, these results can provide important direction for the investing community, particularly hedgers and speculators as a possible basis for investing strategies in the Greater China Region. The knowledge of their volatility dynamics will result in more accurate investment decisions and provide better market perspectives. The general public, as well as the government, can also gain a working knowledge of the patterns of volatility in Greater China Region; and the academic community can gain new insights into the transmission mechanisms in the region, thereby providing future avenues for research. 


\section{References}

Allen, D. E., Amram, R. \& McAleer, M. (2013). Volatility spillovers from the Chinese stock market to economic neighbors. Mathematics and Computers in Simulation, 94, 238-257.

Barari, M., Lucey, B. \& Voronkova, S. (2006). Re-assessing co-movements among G7 equity markets: Evidence from iShares. Applied Financial Economics, 18(11), 863-877.

Working Paper no. WP 06-01. Manchester Metropolitan University.

Bauwens, L., Laurent, S. \& Rombouts, J. (2006). Multivariate GARCH models: A survey. Journal of Applied Econometrics, 21, 79-109.

Bollerslev, T. (1990). Modeling the coherence in short-run nominal exchange rates: A multivariate generalized $\mathrm{ARCH}$ model. Review of Economics and Statistics, 72, 498-505.

Bubak, V., Kocenda, E. \& Ikes, F. (2011). Volatility transmission in emerging European foreign exchange markets, Journal of Banking and Finance, 10, 1-13.

Caporin, M. \& McAleer, M. (2008). Scalar BEKK and indirect DCC. Journal of Forecasting, 27, 537-49.

Caporin, M. \& McAleer, M. (2009). Do we really need both BEKK and DCC? A tale of two covariance models. Journal of Economic Surveys, 26(4), 736-751.

Chang, C., McAleer, M. \& Tansuchat, R. (2011). Crude oil hedging strategies using dynamic multivariate GARCH. Energy Economics, 10, $1-12$.

Du, X., Yu, C. \& Hayes, D. (2011). Speculation and volatility spillover in the crude oil and agricultural commodity markets: A Bayesian analysis. Energy Economics, 33, 497-503.

Engle, R. (1982). Autoregressive conditional heteroscedasticity with estimates of the variance of United Kingdom inflation. Econometrica, $50,987-1007$. 
Engle, R. (2002). Dynamic conditional correlation: A simple class of multivariate GARCH models. Journal of Business and Economic Statistics, 20, 339-50.

Engle, R. \& Kroner, F. (1995). Multivariate simultaneous generalized ARCH. Econometric Theory, 11, 122-50.

Engle, R. \& Sheppard, K. (2001). Theoretical and empirical properties of dynamic conditional correlation multivariate GARCH, No. w8554. National Bureau of Economic Research.

Fleming, J., Kirby, C. \& Ostdiek, B. (1998). Information and volatility linkages in the stock, bond and money markets. Journal of Financial Economics, 49, 111-37.

Hafner, C., \& Herwartz, H. (2006). Volatility impulse responses for MGARCH models: An exchange rate illustration. Journal of International Money and Finance, 25, 719-40.

Ho, K., Tsui, A., \& Zhang, Z. (2009). Volatility dynamics of US business cycle: A multivariate asymmetric GARCH approach. Mathematics and Computers in Simulation, 79, 2856-68.

Hosking, J. (1980) The multivariate portmanteau statistic. Journal of American Statistical Association, 75, 602-08.

Jiang, Y., Nie, H., \& Monginsidi, J. Y. (2017). Co-movement of ASEAN stock markets: New evidence from wavelet and VMD-based copula tests. Economic Modelling, 64, 384-398.

Johansson, A. C., \& Ljungwall, C. (2009). Spillover effects among the greater China stock markets. World Development, 37(4), 839 - 851.

Karolyi, G. (1995). A multivariate GARCH model for international transmissions of stock returns and volatilities: The case of the US and Canada. Journal of Business and Economic Statistics, 13, 1-25.

Li, A., Su, Y.Y., \& Qiao, H.Y. (2016). Research on the international interaction of Chinese Stock market-based on network analysis method. Journal of Quantitative and Technical Economics, 8, 113-127. 
Li, W. \& McLeod, A. (1981). Distribution of the residual autocorrelation in multivariate ARMA time-series models. Journal of the Royal Statistical Society B, 43, 231-39.

Liu, Q. \& An, Y. (2011). Information transmission in informationally linked markets: Evidence from US and Chinese commodity futures markets. Journal of International Money and Finance, (30)5, 778-95.

Malliaropulos, D. (1997). A multivariate GARCH model of risk premia in foreign exchange markets. Economic Modelling, 14, 61-79.

McAleer, M. (2005) Automated inference and learning in modeling financial volatility, Econometric Theory, 21, 232-61.

McAleer, M., Chan, F. \& Marinova, D. (2007). An econometric analysis of asymmetric volatility: Theory and application to patents. Journal of Econometrics, 139, 259-284.

Moon, G. H., \& Yu, W. C. (1991). Volatility spillovers between the US and the China stock markets: Structural break test with symmetric and asymmetric GARCH approaches. Global Economic Review, 39(2), 129-149.

Morrison, W. M. (2003). Taiwan's accession to the WTO and its economic relations with the United States and China. Congressional Research Service, Library of Congress.

Silvennoinen, A., \& Terasvirta, T. (2008). Mulfivariate GARCH models. SSE/EFI Working Paper Series in Economics and Finance, No. 669, Stockholm, Sweden: Stockholm School of Economics.

So, M. K., \& Tse, A. S. L. (2009). Dynamic modeling of tail risk: Applications to China, Hong Kong and Other Asian Markets. AsiaPacific Financial Markets, 16(3), 183-210.

Tse, Y. (2000). A test for constant correlations in multivariate GARCH model. Journal of Econometrics, 98, 107-27.

Tse, Y. \& Tsui, A. (2002). A multivariate GARCH model with time-varying correlations. Journal of Business and Economic Statistics, 20, 351-62. 
Worthington, A., Kay-Spratley, A. \& Higgs, H. (2005). Transmission of prices and price volatility in Australian electricity spot markets: A multivariate GARCH analysis. Energy Economics, 27(2), 337-50.

Yi, Z., Heng, C., \& Wong, W. K. (2009). China's stock market integration with a leading power and a close neighbor. Journal of Risk and Financial Management, 2(1), 38-74.

Yilmaz, K. (2010). Return and volatility spillovers among the east Asian equity markets. Journal of Asian Economics, 21(3), 304-313.

Zhang, C. (2017). Analysis of the Linkage between China and European and American Stock Markets. Social Sciences Frontier, (6), 260-264.

Zhu, J. (2009). Testing for expected return and market price of risk in Chinese A and B share markets: A geometric Brownian motion and MGARCH model approach. Mathematics and Computers in Simulation, 79, 2633-53. 